\title{
Gentrificação e políticas de reabilitação urbana em Portugal: uma análise crítica à luz da tese rent gap de Neil Smith
}

\author{
Gentrification and urban regeneration policies in Portugal: \\ a critical analysis in light of Neil Smith's rent gap thesis
}

Luís Mendes

\begin{abstract}
Resumo
0 artigo problematiza o papel que as políticas de reabilitação urbana no centro histórico das cidades portuguesas detêm no facilitar do processo de gentrificação, afirmando-se como condições necessárias, não sendo, todavia, por si só suficientes para induzir tal processo socioespacial. Ainda assim, os programas de reabilitação urbana, ao visarem estimular a requalificação de edifícios e criar condições favoráveis à atração de capitais privados para a regeneração das áreas da cidade centro, constituem um fator estratégico para a fixação das novas classes médias, contribuindo, em última análise, para a expulsão de antigos moradores, promovendo segregação residencial e desenvolvimento urbano desigual. A problemática será enquadrada pela tese de rent gap de Neil Smith mobilizando os aspectos estruturais do processo de acumulação de capital (e dos seus movimentos cíclicos) e relacionando-os com o (re)desenvolvimento urbano e com a produção de ambiente construído pela gentrificação.
\end{abstract}

Palavras-chave: gentrificação; reabilitação urbana; Portugal; Neil Smith.

\begin{abstract}
The article discusses the role that urban regeneration policies in the historic centers of Portuguese cities play in facilitating the process of gentrification, as they consolidate themselves as conditions that are necessary, but not sufficient to induce, by themselves, this socio-spatial process. Still, the urban regeneration programs, in stimulating the redevelopment of buildings and creating favorable conditions to attract private capital for the redevelopment of areas in the city center, are a strategic factor to the establishment of the new middle-classes. It is possible to say that they contribute to the expulsion of former residents, promoting residential segregation and uneven urban development. The problem is framed by Neil Smith's rent gap thesis. The structural aspects of the capital accumulation process (and its cyclical movements) are mobilized and related to the urban (re)development and to the production of environments built by gentrification.
\end{abstract}

Keywords: gentrification; urban regeneration; Portugal; Neil Smith. 


\section{Introdução}

Um dos pontos de polêmica em torno da gentrificação das áreas centrais da cidade reside na associação imediata deste processo à reabilitação urbana. Se é certo que a reapropriação de um espaço de habitat antigo e por vezes em estado de degradação urbanística acentuada implica, necessariamente, a presença de um processo prévio de reabilitação do edificado, não é menos certo que a gentrificação não pode ser vista como consequência automática de políticas de reabilitação, conservação ou renovação urbana, ou de qualquer política de incentivo ao investimento privado no sentido da reabilitação de edifícios de habitação.

A hipótese é a de que as políticas de reabilitação urbana nos centros históricos das cidades portuguesas poderão facilitar o processo de gentrificação, no entanto são apenas condições necessárias, não sendo por si só suficientes para induzir tal processo socioespacial. Ainda assim, os programas de reabilitação urbana, ao visarem estimular a requalificação de edifícios e criar condições favoráveis à atração de capitais privados para a requalificação das áreas de reabilitação urbana, constituem um fator estratégico para a fixação das novas classes médias na cidade centro, que eleva os valores imobiliários praticados nas áreas afetadas, contribuindo para um desalojamento e expulsão dos grupos socioeconômicos mais desfavorecidos, culminando com um aprofundamento da fragmentação urbana e da divisão social do espaço residencial da cidade.
Impõe-se, então, a procura de eixos explicativos para o processo de gentrificação, nas próprias mudanças socioeconômicas mais profundas e mais amplas que atravessam atualmente as sociedades (e as cidades em particular) dos países desenvolvidos de capitalismo tardio e avançado, argumentando a partir dos apontamentos que a tese de rent gap de Neil Smith ressalva quanto aos aspectos estruturais do processo de acumulação de capital (e dos seus movimentos cíclicos) e relacionando-os com o (re)desenvolvimento urbano e com a produção de ambiente construído. Desta forma, o texto que apresentamos configura tão e somente um mero ensaio teórico, problematizador e exploratório dessa temática, reconhecendo que carece de referência a casos empíricos concretos. Seguindo uma metodologia hipotético-dedutiva, a construção deste ensaio parte de postulados ou conceitos já estabelecidos na literatura consultada, através de um trabalho lógico de relação de hipóteses, que configura, a nosso ver, e embora desprovido de trabalho empírico, uma possível perspectiva de interpretação dos fenômenos em estudo e enquadramento à análise de conteúdo dos vários programas de reabilitação urbana que se foram sucedendo nos últimos 40 anos em território português. Privilegiaremos a abordagem crítica de Neil Smith para apreender a natureza inter-relacionada entre o desenvolvimento capitalista e a produção social do espaço urbano, mediada pelo processo de gentrificação e pelas políticas públicas de reabilitação urbana de um Estado Capitalista que voluntária ou involuntariamente o parecem promover. 


\section{Gentrificação: mapeando o conceito a partir da teoria urbana crítica}

Desde há cerca de meio século, o conceito de gentrificação vem designar um processo de recomposição (e substituição) social verificado no espaço urbano, ligado muitas vezes a ações de reabilitação urbana das habitações nos centros antigos das cidades, mediante investimentos quer públicos quer privados. Por definição, a gentrificação passou, assim, a designar o movimento de chegada de grupos de estatuto socioeconômico mais elevado, geralmente jovens e de classe média, a áreas centrais desvalorizadas da cidade. 0 efeito é que essas áreas se tornam social, econômica e ambientalmente valorizadas, sofrendo um processo de filtering up (Hall, 1998). É um processo de mudança socioespacial, no qual a reabilitação de imóveis residenciais situados em bairros da classe trabalhadora ou de gênese popular/tradicional atrai a fixação de novos moradores relativamente endinheirados, levando ao desalojamento de ex-residentes que não podem mais pagar o aumento dos custos de habitação que acompanham a regeneração (Pacione, 2001). Por conseguinte, é um processo pelo qual os bairros pobres e de classe trabalhadora na cidade centro são requalificados, com a entrada de fluxos de capital privado e de proprietários e inquilinos da classe média e média-alta.

Gentrification is the process [...] by which poor and working-class neighborhoods in the inner city are refurbished via an influx of private capital and middle-class homebuyers and renters - neighborhoods that had previously experienced disinvestment and a middle-class exodus. [...] a dramatic yet unpredicted reversal of what most twentieth-century urban theories had been predicting as the fate of the central and inner-city. (Smith, 1996, p. 32)

Na verdade, indica um processo de emburguesamento de bairros históricos, ou seja, uma acentuação da conotação residencial alto-burguesa ou mesmo uma transformação nesse sentido de bairros anteriormente conotados de maneiras diferentes. Trata-se de um fenômeno de substituição social classista e de reapropriação pela burguesia - e respectiva ideologia neoliberal e ordem simbólica subjacente - dos espaços de habitat populares das áreas antigas centrais (Bourdin, 1979; Rodrigues, 1992b), que implica expulsão dos antigos residentes, logo desalojamento e segregação residencial, culminando com um aprofundamento da divisão social do espaço urbano. Essas tendências são muito evidentes sobretudo numa extensão do conceito de gentrificação a recentes casos de grandes operações urbanísticas de renovação e regeneração, levadas a cabo por diversos agentes de produção do espaço urbano, já caracterizados por Lefebvre (1974): os proprietários fundiários, os promotores imobiliários, o Estado, as empresas e os cidadãos. A gentrificação sempre esteve muito associada a processos mais ou menos vastos de reestruturação urbana como sendo os de: renovação, reabilitação, regeneração e/ou requalificação urbanas (Mendes, 2013).

De acordo com o vocabulário da Direção Geral de Ordenamento do Território e Desenvolvimento Urbano (DGOTDU, 2005) - e também de acordo com a síntese apresentada em Mendes (2013) - por reabilitação urbana 
devemos entender um processo de transformação urbana, compreendendo a execução de obras de conservação, recuperação e readaptação de edifícios e de espaços urbanos, com o objetivo de melhorar suas condições de uso e habitabilidade, conservando, porém, seu esquema estrutural básico e o aspecto exterior original. Portanto, o conceito de reabilitação urbana supõe o respeito pelo caráter arquitetônico dos edifícios, não devendo, no entanto, confundir-se com o conceito mais estrito de restauro, o qual implica a reconstituição do traçado original de edifícios, no mínimo, das fachadas e das coberturas.

Reabilitação urbana não se confunde também com renovação urbana. São conceitos diferentes e que, igualmente segundo a DGOTDU (2005), se distinguem sobretudo pelo tipo de obras inerentes às respectivas operações: na reabilitação urbana alega-se o respeito pelo caráter arquitetônico dos edifícios, enquanto na renovação urbana é permitido o processo mais ou menos pontual de demolição e reconstrução. A renovação urbana é uma ação que implica a demolição das estruturas morfológicas e tipológicas existentes numa área urbana degradada e a sua consequente substituição por um novo padrão urbano, como novas edificações. Por conseguinte, essas intervenções de renovação urbana desenvolvem-se sobre tecidos urbanos degradados, aos quais não se reconhece valor como patrimônio arquitetônico e histórico.

Assim, o processo de reabilitação urbana abrange um vasto leque de intervenções que pode ir desde a simples recuperação do edificado e dos espaços públicos; a uma estratégia de caráter social e assistencial dirigida a problemas específicos de grupos que são socioespacialmente marginalizados e segregados; até a ações mais abrangentes de revitalização social e econômica. Associado ao conceito de reabilitação surge também o de requalificação que visa restituir a qualidade a um determinado espaço, com a melhoria das condições físicas dos edifícios e/ou dos espaços urbanos, podendo ser alterada a função primitiva de forma a dar resposta às exigências da época. Igualmente, e pelo menos no caso português, o conceito de requalificação urbana confunde-se muito com o de regeneração urbana.

Peter Roberts e Hugh Sykes na introdução do livro Urban Regeneration: A Handbook, de 2000, referem a regeneração urbana como sendo um tipo de intervenção largamente experenciado de há umas décadas para cá e que surge essencialmente como tentativa deliberada de contrariar as forças e os fatores que numa determinada conjuntura são a causa da degeneração urbana. Os autores propuseram a seguinte definição:

[Urban regeneration] is a comprehensive and integrated vision and action which leads to the resolution of urban problems and which seeks to bring about a lasting improvements in the economic, physical, social and environmental condition of an area that has been subject to change. ${ }^{1}$ (Roberts e Sykes, 2000, p. 17)

Embora todos esses conceitos tenham subjacente a ideia de transformação urbana, independentemente do seu grau ou intensidade, e de melhorias (improvements) na vida urbana de uma forma geral, em função de diferentes registros de intervenção no espaço urbano, a verdade é que todos eles estão comumente associados a processos de gentrificação, até pelo 
processo voluntário ou não, mas sempre classista, de substituição social que produzem no tecido socioespacial da cidade contemporânea.

Num esforço de revisão da literatura sobre a evolução do conceito de gentrificação, Savage e Warde (1993) defendem que, para que esse processo ocorra no espaço urbano, tem de se dar uma coincidência de quatro processos: 1) uma reorganização da geografia social da cidade, com substituição, nas áreas centrais da cidade, de um grupo social por outro de estatuto mais elevado; 2) um reagrupamento espacial de indivíduos com estilos de vida e características culturais similares; 3 ) uma transformação do ambiente construído e da paisagem urbana, com a criação de novos serviços e uma requalificação residencial que prevê importantes melhorias arquitetônicas; 4) por último, uma mudança da ordem fundiária, que, na maioria dos casos, determina a elevação dos valores fundiários e um aumento da quota das habitações em propriedade. ${ }^{2}$

A gentrificação não é um fenômeno novo, contudo as suas atuais formas distinguem-se dos primeiros episódios pontuais que se restringiam à cidade centro. As principais diferenças entre as novas formas de gentrificação dos anos 1990 e a forma clássica do fenômeno do início dos anos 1970 são a escala e a extensão. Diversos estudos urbanos nos últimos vinte anos têm relacionado a difusão do processo de gentrificação, para além do característico perímetro central da cidade, com as numerosas intervenções de renovação e regeneração urbanas, verificadas ao longo dos anos 1980 e 1990 em muitas cidades e por vezes favorecidas ou mesmo incentivadas pelas intenções políticas neoliberais dos governos urbanos (Mayer, 2007; Hackworth, 2007; Harvey, 2011). De anomalia local e esporádica, limitada à cidade centro, a gentrificação passou a constituir-se como estratégia de mercado. É a (super)gentrificação como estratégia global ao serviço do urbanismo neoliberal e revanchista e dos interesses da reprodução capitalista e social, cuja crítica Smith $(1996,2001,2002,2005)$ se esforçou nos últimos anos por desenvolver.

A gentrificação, nesses casos - e à luz da evolução das transformações significativas que o mercado de habitação das cidades do capitalismo avançado tem sofrido, como Neil Smith demonstrou - sofre mutações, pois deixa de estar única e exclusivamente associada à reabilitação urbana e passa a estar cada vez mais ligada à regeneração ou mesmo à renovação de inteiros bairros de habitação, situados no centro ou nas suas proximidades e na sua substituição por conjuntos de construções de luxo, integrados, com serviços qualificados, ou outras modalidades de residências de alta qualidade, novos produtos imobiliários destinados a camadas de rendimentos elevados, todos correspondendo a formas espaciais de autossegregação burguesa ou "segregação voluntária" como adianta Villaça (1998) - relativamente à cidade da maioria (Lees, Slater e Wyly, 2008).

Nos seus escritos mais recentes Neil Smith deixa claro que os projetos de regeneração urbana a favor de uma economia vibrante e criativa, e que suportam a promoção ideológica da gentrificação, ${ }^{3}$ alimentam equívocos vários no que diz respeito às supostas intenções iniciais de reabilitação habitacional e integração/fixação da população de menor estatuto socioeconômico já anteriormente residente nos bairros históricos alvo de intervenção. De resto, nesses contextos como nos restantes que emprestaram o cunho classista 
ao conceito, o filtering up que a gentrificação pressupõe - pelo processo de substituição social que implica, de classes de menor estatuto socioeconômico pelas de maior - faz antever o acentuar dos traços de segregação socioespacial nas áreas onde o fenômeno tem lugar. 0 desenvolvimento de parcerias público-privado, que nesse quadro é frequente desenhar-se, constitui um verdadeiro subsídio aos mais ricos, ao tecido empresarial mais poderoso e às funções e relações estratégicas de controle, poder e dominação do espaço urbano, condição fundamental na perpetuação da reprodução do capital, premissa essencial para o suporte do sistema de produção e consumo capitalista. Tudo isso à custa dos investimentos em serviços locais de consumo coletivo. É que se, em última análise, a atração e o crescimento propiciados pela gentrificação a todos beneficiam, em primeiro lugar ganham os promotores imobiliários e as empresas, muito frequentemente à custa da expulsão dos residentes e das empresas mais débeis dos lugares requalificados, lançados por via dessa (des)valorização, num processo de exclusão e de marginalidade socioespacial. Algo diretamente correlacionado com modelações ideológicas que visam a manutenção da reprodução social das classes de maior estatuto socioeconômico.

A literatura sobre a gentrificação em geral já é extensa e continua a expandir-se. Muitos contributos para essa literatura citam a importância do processo para o desenvolvimento econômico urbano e apontam que o discurso "regenerativo" da gentrificação no âmbito de políticas urbanas de valorização da imagem da cidade visam: a fixação da população já existente; a estabilização e posterior inversão do cenário de declínio urbano de muitas áreas urbanas sobretudo centrais; defesa de um modelo de cidade mais consolidada e compacta em torno do centro, ao invés de um modelo de crescimento e expansão urbana (suburban spraw); um incremento do mix social, favorecendo os mais pobres e as minorias através de um "efeito de bairro" promovido por políticas de habitação de mix residencial; o empowerment das associações e outras organizações locais; a modernização do tecido econômico, com a redinamização do comércio local e tradicional de bairro e o aumento do emprego e do crescimento econômico locais, bem como a melhoria da qualidade de vida urbana em geral (Atkinson e Bridge, 2005; Lees, Slater e Wyly, 2008). Outros contestam as ideologias neoliberais e os efeitos da segregação, polarização e exclusão social inerentes à aplicação da agenda de consensos e de pensamento único hegemônico da cidade dual. São conhecidas as transformações nefastas na paisagem urbana que acompanham o surgimento e do desenvolvimento urbano de políticas baseadas na regeneração e reurbanização urbanas.

Para além de Neil Smith, nas obras já citadas, também Atkinson (2003), Harvey (2011, $2012,2014)$ e Lees $(2008,2009)$ são alguns dos autores que se têm destacado na crítica da gentrificação, sendo essa enquadrada na discussão de políticas urbanas ao serviço da ideologia neoliberal e da produção de uma cidade revanchista. Na prática, defendem que o processo, apesar de se revestir algumas vezes daqueles aspectos mais positivos, não deixa também de funcionar como mecanismo de legitimação do poder instituído e da mobilização do grande investimento público que, em última análise, é desviado do auxílio aos mais carenciados, funcionando pelo princípio 
da "privatização dos lucros e socialização dos custos" para financiamento das atividades predatórias e de especulação imobiliária levadas a cabo pelos agentes de produção do espaço urbano, de si já mais favorecidos, tais como, a Banca, as instituições financeiras em geral, os grandes grupos econômicos e de construção civil, os promotores imobiliários, os empreendedores, entre outros.

As intervenções públicas que provocam valorização da cidade "gentrificada" desencadeiam mecanismos contraditórios de expulsão e de reapropriação. As intervenções públicas que favorecem as ações de reabilitação e regeneração urbana, determinadas, igualmente, pela necessidade de melhorar a imagem da cidade, de a tornar mais criativa e atrativa num quadro e cenário estratégicos de competitividade interurbana global; implicam, muito frequentemente, a expulsão de habitantes de menor estatuto socioeconômico das áreas centrais, condenando-os, doravante, a uma marginalidade socioespacial em áreas de periféricas.

Smith (1979a, 1986a, 1987a) insiste no fato de o processo de gentrificação resultar, em parte, do desenvolvimento irregular e flexível do mercado do solo urbano, integrando-se no processo de acumulação de capital, fazendo-o derivar, mais especificamente, do movimento e circulação de capital nas áreas urbanas, tendo em conta a desvalorização que sofre o solo urbano, diante do rendimento que um novo investimento poderia ter. No início do fenômeno, o abandono e a degradação da cidade centro, de acordo com o autor, criam justamente a futura oportunidade de valorização e negócio imobiliário nos bairros centrais, tornando-os atrativos para o investimento público e privado e para a exploração de mais- -valias resultantes da diferença entre a atual renda capitalizada diante do presente uso do seu solo, e a renda que potencialmente poderá a vir a ser capitalizada tendo em conta sua localização central. É, aliás, esse o argumento central da tese de rent gap que o autor vinha a defender há mais de 30 anos e que criou, per se, um paradigma e escola de análise urbana sobre o fenômeno da gentrificação, tendo influenciado, doravante e de forma marcante, 0 pensamento que se produziu na, da e para a teoria crítica urbana nos anos vindouros. A tese do rent gap continua hoje a explicar as geografias da gentrificação, e a ser o móbil que legitima determinadas políticas de cidade para a reabilitação e a regeneração, levadas a cabo pelos governos urbanos. Essa tese de Smith será apresentada de forma mais cuidada e detalhada no próximo ponto.

\section{A tese do rent gap, os movimentos cíclicos de capital e o desenvolvimento desigual na produção do espaço urbano}

0 espaço urbano é produzido histórica e socialmente, na medida em que é uma componente da produção social em geral e revela igualmente uma lógica resultante das relações entres os diferentes grupos sociais num determinado momento histórico. No momento presente e num passado recente, o espaço como produto social é construído e reconstruído à luz da racionalidade capitalista contemporânea. Esse quadro obriga, pois, à necessidade de entender a dinâmica dos espaços urbanos ligada a 
processos concernentes ao funcionamento do próprio capitalismo e do seu modo de produção específico. Uma vasta literatura científica consolidada nos estudos urbanos demonstra como as relações espaciais e capitalistas estão articuladas dialeticamente. Se as necessidades de capital se manifestam no espaço, as mudanças espaciais manifestam-se nas necessidades de capital. Todos os analistas urbanos que propõem estudos a partir desse princípio teórico concordariam com a ideia de que o estudo da gentrificação na produção social do espaço requer uma análise do processo de acumulação capitalista. A acumulação de capital - ou a produção de mais-valia - é a força que impulsiona a sociedade capitalista. Por regime de acumulação pode entender-se o conjunto de princípios de organização da economia, que asseguram determinadas condições de produção (forma de organização do trabalho, tecnologia empregue, base energética, opções de localização, estratégias de armazenagem, etc.) e de ligação dessa ao consumo (circuitos e formas de distribuição, formas de marketing e publicidade, etc.). Por sua própria natureza, a acumulação de capital necessita da expansão dos meios de produção, da expansão do tamanho da força de trabalho assalariada, da expansão da atividade de circulação na medida em que mais produtos se tornam mercadorias e da expansão do campo de controle da classe capitalista dominante. É o garante da reprodução das relações de produção, que se cumpre, em primeiro lugar, pela materialidade do processo de produção e do processo de circulação (Harvey, 1975, 1978, 1985, 2001, 2006, 2010, 2013).

A partir dessa perspectiva, os teóricos da geografia crítica e radical explicam que os processos de desenvolvimento da cidade ou urbanização são a manifestação espacial do processo de acumulação de capital. Na prática, os defensores dessa tese ressaltam os aspectos estruturais desse processo e relacionam-nos com o desenvolvimento urbano. De motor de crescimento, a cidade tornou-se um espaço organizado para o investimento de capital. As contradições experimentadas no espaço construído são reproduzidas por causa dos passos dados para converter o capital financeiro no elo mediador entre o processo de urbanização (em todos os seus aspectos, inclusive a edificação de ambientes construídos) e as necessidades ditadas pela dinâmica subjacente do capitalismo (Lefebvre, 1972).

Esse ponto obriga-nos a revisitar a relação entre a produção do espaço construído e as crises no processo de acumulação de capital estudada por David Harvey, princípio de incontornável influência na obra de Neil Smith. 0 primeiro autor identifica três circuitos distintos de acumulação de capital. 0 circuito primário, que se refere à organização do próprio processo produtivo, como a aplicação de tecnologia e trabalho assalariado para produzir bens em troca de lucro. 0 circuito secundário, que implica investimento no ambiente construído. E, finalmente, o circuito terciário, que diz respeito ao investimento em ciência e tecnologia e numa ampla gama de despesas sociais relacionadas, principalmente, com os processos de reprodução da força de trabalho. A competição entre capitalistas resulta em superacumulação. Capital em demasia é produzido no geral, comparativamente à existência de oportunidades de empregar esse capital. Uma solução temporária para esse problema é uma mudança do fluxo de capital para outros circuitos. Quando isso é feito em relação 
ao circuito secundário, tal resulta na produção do ambiente construído. Por conseguinte, na perspectiva de Harvey, o montante periódico de investimento e a consequente valorização do ambiente construído estão claramente indicados nos ritmos cíclicos do processo de investimento de capital no espaço.

A dinâmica dos ciclos de investimento e desinvestimento do capitalismo explica os estágios na construção do ambiente construído. Barata Salgueiro (1994, p. 91) sintetiza da seguinte forma:

Do ponto de vista da circulação do capital, os booms imobiliários coincidem com a transferência do capital do circuito primário de acumulação (a esfera produtiva) para o circuito secundário (produção do ambiente construído) [...] em épocas de excesso de liquidez e problemas de acumulação registadas no processo produtivo.

A percentagem do capital fixo destinado ao setor da habitação - cerca de $20 \%$ da formação total de capital - revela a preferência pela propriedade urbana como forma de aplicação de capitais, com prejuízo dos empreendimentos agrícolas e industriais, em que os coeficientes de risco são geralmente superiores. A mesma preferência pela especulação e pela propriedade imobiliária origina, com muita frequência, um luxo espetacular das construções, cujo interesse social se tem de considerar nulo, quando não negativo, na medida em que reduz, para um dado investimento, o número de pessoas que é possível alojar (Silva Pereira, 1963).

À luz desse princípio, Smith (1979a, 1979b, 1982, 1984, 1986a, 1986b, 1987a, 1992,
1996) procura explicar a reestruturação do espaço urbano como um processo intimamente ligado à própria reestruturação da economia capitalista, mais precisamente, aos ciclos macroeconômicos de evolução irregular que marcam o desenvolvimento das sociedades de capitalismo avançado. Segundo o autor - e à semelhança do pensamento de Harvey - o desenvolvimento do capitalismo resultou, em parte, na superprodução das comodidades geradas, 0 que provocou uma inevitável quebra dos lucros no domínio da produção e, consequentemente, uma crise no seu interior. Desse modo, na sua concepção, essa crise do capitalismo só conseguiu ser atenuada e superada por intermédio de novas oportunidades e de novas formas de canalização do investimento para setores que permitissem uma rápida e eficaz reprodução, designadamente, 0 imobiliário. Portanto, percebe-se que a partir do pós-guerra, aquele passou a dirigir-se preferencialmente para o setor da construção, em detrimento do setor tradicional da produção industrial, gerando importantes recomposições na expansão e organização espacial da forma urbana (Gottdiener, 1985).

0 ambiente construído tornou-se o cenário de altos e baixos cíclicos no mercado imobiliário, com a existência paralela de deterioração e de superconstrução. Os dois fenômenos são produzidos pelo processo de construção na cidade sob relações sociais capitalistas e têm subjacente a ideia de que o crescimento urbano desigual é intrínseco à natureza capitalista de desenvolvimento. Inaugura-se, dessa forma, um novo ciclo: o da valorização/ desvalorização do espaço urbano nos mercados regionais de solo, com início do processo de suburbanização. 
Os processos de suburbanização e emergência do rent gap são designados por Smith (1986a) como predominantemente responsáveis pela forma como o processo de reestruturação urbana se apresenta nos dias de hoje. Isso porque o movimento de saída de capital para a periferia provoca uma alteração inversamente proporcional dos níveis de renda do solo dos próprios subúrbios e dos bairros centrais: enquanto o valor do solo nos subúrbios aumenta significativamente com 0 crescimento de novas construções e infraestruturas, e com a consequente introdução nesses espaços de uma multiplicidade de atividades, o valor fundiário dos bairros centrais, ao invés, sofre uma progressiva diminuição, sendo cada vez menor a quantidade de capital canalizado e investido na manutenção, reparação e recuperação do parque habitacional dessas áreas no interior das cidades.

Deste fenômeno resultou o que Smith (1987a) denominou emergência da rent gap nos bairros centrais - acentua-se a diferença entre a atual renda capitalizada diante do presente uso do seu solo, e a renda que potencialmente poderá a vir a ser capitalizada tendo em conta sua localização central. É precisamente o movimento de saída de capital para os subúrbios e o consequente surgimento do fenômeno rent gap no espaço urbano central que, segundo o autor, cria maiores oportunidades econômicas para a reestruturação urbana dos bairros centrais e para o investimento público e privado, na reabilitação e recuperação do seu parque habitacional e que corresponde a um fenômeno de ocorrência quase universal em todas as cidades das sociedades de capitalismo avançado.
A conclusão lógica da aplicação do princípio rent gap decorre do princípio da análise urbana marxista de que o desenvolvimento espacial desigual e a desvalorização periódica do espaço construído (neste caso, as áreas históricas do centro da cidade que se vão degradando progressivamente) são "funcionais" e produzidos intencional e deliberadamente para garantir o futuro investimento de capital e a respectiva reprodução. Para cada "zona de crescimento" que representa uma área de intensa atração de investimento (subúrbio), existe uma "zona de transição" (centro histórico), onde o capital fixo é desvalorizado antes que os especuladores tirem vantagem do redesenvolvimento. 0 desenvolvimento desigual é intensificado pela necessidade funcionalista do processo de acumulação de capital em desvalorizar os seus investimentos passados, de forma a melhor se reproduzir por via de uma "destruição criativa", na medida em que a eficácia inerente à lógica de reprodução capitalista reside precisamente nos movimentos cíclicos dos fluxos de capital e da sua contínua mobilidade e circulação constantes (Smith, 1984; Gottdiener, 1985).

Desse modo, com a fase de suburbanização do capital e com os investimentos canalizados para a periferia, certos bairros centrais da cidade, sofrendo um processo de desinvestimento nas suas áreas, passaram a capitalizar significativamente abaixo do seu potencial valor de renda. Contudo, mais recentemente, a procura de localizações para um investimento seguro e lucrativo em áreas metropolitanas, e diante de um solo suburbano já saturado e mais dispendioso, canalizou o capital público e privado para aquelas áreas subvalorizadas (atendendo à sua localização central), 
empreendendo-se ações (desde a reabilitação à simples especulação imobiliária) visando a obtenção de lucros através da diferença entre a renda capitalizada real e a potencial.

Na espacialização diferenciada de desenvolvimento desigual está a lógica e a tendência do capital em direção àquilo que Smith e Harvey designam de movimento cíclico do capital. 0 capital move-se para onde a margem de lucro é máxima e as possibilidades de reprodução do investimento são mais elevadas, e seus movimentos são sincronizados com os ritmos da acumulação e crise, sempre numa grande diversidade de escalas. A mobilidade do capital acarreta o desenvolvimento de áreas com alta taxa de lucro e o subdesenvolvimento daquelas áreas onde se verifica uma baixa taxa de lucro. Na escala urbana, o aparecimento de áreas subdesenvolvidas conduz a um rápido crescimento na renda do solo e à frustração, após um certo tempo, de maior desenvolvimento, conduzindo à especulação. Não se pode negar que o problema do custo do solo urbano seja válido para muitos países e daqui decorre justamente o elevado poder explicativo da narrativa marxista aplicada ao estudo urbano da gentrificação.

Aliás, é generalizável a vários países de capitalismo tardio, a preferência pela construção de imóveis com numerosos pisos (verticalização da cidade) que permite encarar a utilização do solo urbano em bases mais econômicas, sobretudo tendo em conta o custo da extensão dos aglomerados urbanos, em meios de comunicação e abastecimento, bem como em outros serviços. Mas essa economia é muitas vezes anulada ou reduzida, pelo encarecimento do solo que desse modo se provoca. Assim, o preço dos bens imobiliários é estabelecido no mercado pelo jogo normal da oferta e da procura. Se a segunda for muito superior à primeira, geram-se situações de especulação imobiliária, ou seja, operações de transação de propriedades envolvendo lucros exorbitantes. Assim, torna-se especialmente difícil evitar a subida do preço do solo urbano quando representativa de mais-valias decorrentes do próprio desenvolvimento econômico, mesmo que para esse desenvolvimento os seus detentores em nada tenham contribuído. Este fato é característico dos períodos de crescimento econômico rápido, quase sempre acompanhados de intenso urbanismo, incidindo sobre um número limitado de polos de atração, procedendo a uma seletividade estratégica territorial no investimento de capital imobiliário. Aliás, os próprios usos competitivos do solo urbano são geograficamente selecionados, em primeiro lugar, mediante o sistema de renda do solo. Por vezes, é o próprio Estado que procura cobrar, através de impostos especiais sobre as transações imobiliárias, a margem excedentária, fazendo reverter para os cofres públicos o produto de uma sobrevalorização baseada, com frequência, nos seus próprios investimentos (Barata Salgueiro, 1983).

0 subdesenvolvimento das áreas centrais da cidade por via do abandono e da degradação sociourbanística - que com frequência é intencional - eventualmente conduz justamente àquelas condições que configuram uma área altamente lucrativa e susceptível de rápido (re)desenvolvimento. A destruição criativa de capital que acompanha as crises capitalistas sempre prepara terreno para uma nova fase de desenvolvimento capitalista (Harvey, 2001, 2006, 2010, 2013, 2014). 0 subdesenvolvimento, como o desenvolvimento, ocorre em todas 
as escalas espaciais, mas é à escala urbana que o padrão atinge o seu máximo desenvolvimento. 0 capital tenta constantemente movimentar-se no espaço urbano de tal forma que incessantemente possa explorar as oportunidades de desenvolvimento emprestadas pelas vantagens comparativas oferecidas por cada área da cidade ao (re) investimento imobiliário, sem sofrer os custos econômicos do subdesenvolvimento. Isto é, o capital tenta fazer um movimento cíclico de uma área desenvolvida para uma área subdesenvolvida, para então, num certo momento posterior, voltar à primeira área que agora se encontra subdesenvolvida (devido à sua privação temporária de capital), e assim sucessivamente. 0 capital recorre à completa mobilidade como substituto de um fixo espacial, desprendendo-se dos custos da fossilização do capital no ambiente construído, procurando nesse constante desequilíbrio de (re)apropriação para investimento no espaço urbano, um equilíbrio que seja viável precisamente na sua capacidade de se deslocar no espaço intrametropolitano de maneira sistemática. 0 vaivém do capital do espaço desenvolvido para o subdesenvolvido, e o seu retorno para aquele novamente, apenas é a expressão geográfica do constante e necessário movimento do capital fixo para o circulante, e novamente desse para aquele, como meio de contrabalançar a decrescente taxa de lucro (Santos, 1979; Smith, 1982, 1984).

Em suma, o processo de gentrificação resulta, em parte, do desenvolvimento irregular e flexível do mercado do solo urbano, integrando-se no processo de acumulação de capital e no respectivo movimento cíclico dos fluxos de circulação de umas áreas para outras. Mas, se a reestruturação do espaço na escala urbana, e o rent gap, através da recomposição de uso e funções na cidade centro é válida e consolidada como paradigma explicativo do processo, deve também ser enquadrada num cenário mais amplo de geografia histórica da "glocalização" capitalista, já que a crise atual será superada em primeiro lugar na articulação entre a escala metropolitana e a escala internacional, sendo aí que deve ocorrer a profunda reestruturação. Cria-se, então, a possibilidade que certos tipos de desenvolvimento, anteriormente bloqueados, possam afigurar-se como solução parcial à crise de legitimação do capitalismo contemporâneo (Harvey, 2014).

\section{Breve retrospectiva dos Programas de Reabilitação Urbana em Portugal: um constrangimento ou um incentivo à gentrificação?}

As intervenções no domínio da Reabilitação Urbana em Portugal adquiriram uma importância crescente no decorrer dos últimos 40 anos, revelando-se fundamentais na revitalização dos centros históricos, e até aos anos 1970 do século passado, a reabilitação do patrimônio construído manteve-se circunscrita a monumentos nacionais ou outros edifícios de elevado valor histórico, na sequência de campanhas de pendor nacionalista que pretendiam sobretudo legitimar toda a ideologia ultraconservadora do regime do Estado Novo (Gonçalves, 2006; Matias Ferreira, 2004; Aguiar, 2014). 
0 primeiro programa visando o apoio financeiro à reabilitação dos edifícios foi criado em 1976, o PRID - Programa de Recuperação de Imóveis Degradados. Esse programa tinha como objetivo o de apoiar, através da concessão de empréstimos bonificados às autarquias, mas também aos particulares, 0 desenvolvimento de obras de conservação, reparação e beneficiação do patrimônio habitacional público e privado.

Uma década depois, em 1985, foi criado o PRU - Programa de Reabilitação Urbana que se traduzia no apoio técnico e financeiro às autarquias, prevendo a criação de um Gabinete Técnico Local (GTL) que funcionava na respectiva dependência da câmara municipal e geria todo o processo de reabilitação, atuando, não apenas, sobre o restauro e recuperação dos imóveis, mas, também, sobre as áreas urbanas mais abrangentes onde aqueles se inseriam. Ao abrigo do PRU foram criados 36 GTL's em todo o país, com a missão de elaborarem projetos de reabilitação de áreas urbanas em núcleo histórico, recuperação dos seus edifícios, gestão financeira de reabilitação e apoio social às populações, sustentando-se num apoio técnico especializado às autarquias, prestado por equipas pluridisciplinares (Appleton et al., 1995). As suas atribuições eram fundamentalmente as seguintes: elaborar projetos de reabilitação de espaços comuns e de recuperação de edifícios promovendo e acompanhando as obras; informar e apoiar os proprietários e moradores para dinamizar a sua participação na realização das obras nos edifícios e na obtenção de apoios financeiros; e dar parecer sobre o licenciamento de obras na sua área de intervenção. Os GTL tentavam dar resposta aos problemas específicos da área, planificando, a par da reabilitação física dos bairros, a reabilitação histórica e social, mantendo as reminiscências de tradição e promovendo a qualidade do espaço urbano, quer para os atuais residentes, quer para os vindouros, numa perspectiva de articulação técnica das soluções e numa atitude de participação social dos residentes na zona de intervenção.

A lógica de diálogo e de apoio estabelecida com a população residente no que respeita à melhoria das condições de habitabilidade dos imóveis degradados dos bairros centrais é muito explícita, não só nos discursos, como também nas práticas concretas dos diversos GTL. $A$ área de intervenção envolve grupos sociais diferentes caracterizando-se por uma forte função residencial, com uma população envelhecida, com nível baixo de instrução, mas dotada de um forte enraizamento produzido por graus de relação de intimidade quotidiano, predominando as relações sociais primárias, de proximidade e de vizinhança. A atuação dos GTL sempre foi, assim, norteada pela possibilidade de manutenção da população residente e pela fixação de grupos etários mais jovens, tendo-se quase sempre trabalhado na sensibilização e apoio social da população (CML, 1993).

Para desenvolvimento das operações de reabilitação foi necessário proceder ao desalojamento ou realojamento provisório dos moradores dos edifícios a reabilitar. Durante as obras de reabilitação dos seus imóveis, sobretudo se esses se situassem em áreas críticas de recuperação e reconversão urbanística, aquelas ações foram necessárias para levar a bom termo 0 processo de reabilitação, o que obrigou ao estabelecimento por parte da autarquia de regulamentos normativos para sua orientação respectiva. Assim foi, por exemplo, com a Proposta 
n. 456/87: Realojar, aprovada pela Assembleia Municipal de Lisboa de 1988, que estabelecia, há já vinte e cinco anos, que nenhum desalojamento se processaria sem prévia definição dos moradores desalojados no que diz respeito a vários aspectos: ao conhecimento da posição dos moradores relativamente à habitação que ocupam; ao transporte e salvaguarda dos haveres do desalojado; ao estudo de possíveis consequências do desalojamento nos rendimentos dos moradores desalojados, prevendo a adoção de possíveis medidas, nomeadamente financeiras, para minorar eventuais efeitos negativos; à salvaguarda das condições de saúde dos desalojados, especialmente dos mais idosos; à definição da solução de alojamento definitivo adotado, devidamente fundamentada e subscrita pelo morador. Condições similares são aplicadas no caso de realojamento provisório. Todos os moradores desalojados provisoriamente das suas habitações só o foram quando se demonstrou que o realojamento provisório era a única solução possível para resolver o seu problema de residência, durante as obras de reabilitação. Um objetivo de princípio, repetidamente expresso pela autarquia, sempre consistiu na defesa, o mais possível, do direito das populações autóctones se manterem na sua área de residência habitual, procurando preservar os laços sociais e de entre-ajuda existentes, estabelecidos por meio de fortes relações de vizinhança, que organizam o coeso espaço social dos bairros. Limitava-se assim a intervenção do mercado e da iniciativa privada na promoção de gentrificação.

Passados nem cinco anos da criação do PRU, e uma vez que os resultados alcançados pelos dois programas anteriores nas últimas décadas não eram suficientemente satisfatórios, nomeadamente no que respeita ao parque habitacional arrendado, foi criado o Recria - Regime Especial de Comparticipação na Recuperação de Imóveis Arrendados que visava financiar a execução das obras de conservação e beneficiação, que permitiam a recuperação de fogos e imóveis em estado de degradação, mediante a concessão de incentivos pelo Estado e pelos municípios.

Em 2001, foi criado o Programa de Solidariedade e Apoio à Recuperação e Habitação - SOLARH - que se traduziu num apoio financeiro especial sob a forma de empréstimo sem juros, concedido pelo Instituto Nacional de Habitação a agregados familiares de fracos recursos econômicos, para execução de obras de conservação. Nessa medida, não só se visava facultar aos proprietários abrangidos os meios financeiros necessários à reposição das condições mínimas de habitabilidade, como se pretendia favorecer o aumento da oferta de habitações para arrendamento com valores moderados de renda que sejam compatíveis com os rendimentos de estratos sociais de menor poder de aquisição.

\section{Última década:} crise do Estado Social, estímulos ao mercado privado de reabilitação urbana e efeitos na produção de gentrificação

Este mesmo Estado, que nos anos 1970, 1980 e 1990 apresentava preocupações sociais na política de reabilitação urbana, foi marcado, doravante e a partir do início do século XXI, 
por um quadro de referências neoliberal. Uma nova política urbana de reabilitação, muito mais orientada para o mercado e, portanto, marcada pelas lógicas da promoção do consumo, da competitividade entre metrópoles, do protagonismo dos atores privados no processo de planeamento e de produção da cidade. As administrações centrais têm procurado uma redução gradual dos poderes executivos de todo o setor público, tentando transferir para o setor privado todos aqueles que não tinham necessidade absoluta de ser pelo Estado executados. A maior parte dos governos urbanos assumem posições neoliberais, partindo da convicção de que o investimento privado, quando fomentado pelo mercado, gera emprego e riqueza, produz diretamente bem-estar social na cidade. Reconhece-se nas áreas urbanas abandonadas ou em processo de declínio, áreas-oportunidade, para atrair investimento privado e garantir a reprodução de capital imobiliário. Na reabilitação urbana evidencia-se o papel de relevo do marketing territorial na gestão estratégica da imagem da cidade, de forma a levar a que cada cidade se diferencie das outras, valorizando-se e projetando-se no contexto internacional, atraindo o investimento desejado.

Essa tendência neoliberal de valorização das perspectivas do mercado na produção do espaço urbano fica evidente com a promulgação do Decreto-Lei n. 104, de 7 de maio de 2004, que criou o Regime Jurídico Excepcional de Reabilitação Urbana de Zonas Históricas e de Áreas Críticas de Recuperação e Reconversão Urbanística. Esse regime permitiu às autarquias a possibilidade de constituírem Sociedades de Reabilitação Urbana (SRU) com poderes de autoridade e de política administrativa (como os de expropriação e licenciamento). As SRU tinham como principal função captar investimentos e mobilizar todos os intervenientes (inquilinos, autarquias, senhorios, investidores) de modo a criar um verdadeiro mercado nacional da reabilitação. Sob o discurso de que o Estado e as autarquias não dispõem dos meios financeiros para uma efetiva reabilitação urbana em Portugal, supostamente responsável por uma dinamização pouco efetiva e algo morosa desse importante processo, considera-se a mobilização do investimento privado para a reabilitação urbana. Isso através de parcerias público-privadas, que atraem o capital privado, com recurso a formas imaginativas de engenharia financeira que envolvam mecanismos (como sejam fundos de investimento imobiliários) que permitam a capitalização dos projetos com vista à requalificação do tecido urbano, permitindo 0 suposto "repovoamento" do centro das cidades (CML, 2012).

Para isso, no entanto, é fundamental que o investimento seja rentável, através da criação de um quadro econômico, financeiro e regulamentar que seja susceptível de atrair e potenciar investimento privado. Um sinal disso foi dado pela Lei do Orçamento de 2007, que desceu a taxa do IVA de $21 \%$ para $5 \%$ aplicável às empreitadas de requalificação e reconversão urbana, equiparando o regime fiscal a outros sistemas de reabilitação urbana, o que permitirá a captação de investimentos privados no âmbito das SRU. 0 principal princípio norteador desse regime excepcional é, por conseguinte, o do incentivo econômico à intervenção dos promotores privados no processo de reabilitação.

$\mathrm{Na}$ mesma linha devem ser entendidos os apoios fiscais à reabilitação urbana, enquadrados no Regime Extraordinário de Apoio 
à Reabilitação Urbana (2008-2012), ${ }^{4}$ que, ao visarem estimular a reabilitação de edifícios e criar condições favoráveis à atração de capitais privados para a requalificação das áreas de reabilitação urbana, constituem um fator estratégico para a fixação das novas classes médias na cidade centro. 0 âmbito de aplicação desse novo regime é claro: os prédios urbanos que sejam objeto de ações de reabilitação e satisfaçam, pelo menos, uma das seguintes condições: a) prédios urbanos arrendados e passíveis de atualização faseada das rendas nos termos do Novo Regime de Arrendamento Urbano; b) e prédios urbanos localizados em áreas de reabilitação urbana. Essas áreas são definidas pelo Regime Extraordinário como áreas territorialmente delimitadas, caracterizadas pela degradação ou obsolescência dos edifícios, das infraestruturas urbanísticas, do equipamento social, das áreas livres e do espaço público.

Entretanto, o Decreto-Lei n. 307, de 23 de outubro de 2009, assume a reabilitação urbana como uma componente indispensável da política de cidades e da política de habitação em Portugal, prolongando o regime de incentivos fiscais ao investimento privado no mercado da reabilitação urbana, para além de que passa a incumbir aos privados o dever público de requalificação do parque habitacional e de outras componentes do espaço público. Sob o signo de uma tentativa de compactar o atual quadro legislativo da reabilitação urbana que se diz apresentar um caráter disperso e assistemático, considera-se como objetivo central do presente decreto-lei substituir um regime que regula essencialmente um modelo de gestão das intervenções de reabilitação urbana, centrado na constituição, funcionamento, atribuições e poderes das SRU, por um outro regime que proceda ao enquadramento normativo da reabilitação urbana no nível programático, procedimental e de execução financeira. As entidades gestoras das operações de reabilitação urbana podem corresponder ao próprio município ou a entidades do setor empresarial local existentes ou a criar. Se essas entidades gestoras de tipo empresarial tiverem por objeto social exclusivo a gestão de operações de reabilitação urbana, revestem, à luz da lei anterior, a qualidade de SRU, admitindo-se a participação de capitais do Estado nessas empresas municipais. Em qualquer caso, cabe ao poder público municipal, sempre que não promova diretamente a gestão da operação de reabilitação urbana, determinar os poderes da entidade gestora, por via da delegação de poderes. De modo a promover a participação de particulares nesse domínio, permite-se às entidades gestoras o recurso a parcerias com entidades privadas, as quais podem ser estruturadas de várias formas, prevendo a concessão da reabilitação urbana à administração conjunta entre entidade gestora e proprietários. Finalmente, dedica-se o último capítulo à matéria do financiamento, aspecto fulcral na reabilitação urbana. Embora essa matéria não seja objeto de regulamentação exaustiva, não deixa de ser relevante o fato de se prever com essa lei a possibilidade de concessão de apoios financeiros por parte do Estado e dos municípios às entidades gestoras, abrindo-se caminho à constituição de fundos de investimento imobiliário dedicados à reabilitação urbana.

$\mathrm{Na}$ verdade, está-se a diversificar os modelos de gestão das intervenções de reabilitação urbana, abrindo novas possibilidades de intervenção dos proprietários e outros parceiros privados. Criaram-se também mecanismos 
que permitem agilizar os procedimentos (facilitando as expropriações) de controle prévio das operações urbanísticas de reabilitação. Desenvolveram-se novos instrumentos que permitem equiparar os direitos dos proprietários e do setor privado ao Estado, de forma a remover mais eficientemente os obstáculos à reabilitação associados ao regime de propriedade nessas áreas. Esse processo se não for devidamente acautelado pode significar um reforço do desalojamento e da segregação residencial.

Mais recentemente, a promulgação do Decreto-Lei n. 31, de 14 de agosto de 2012, institui a nova lei do arrendamento urbano, também conhecida por Novo Regime de Arrendamento Urbano (NRAU), e que entrou em vigor em novembro de 2012, está a ser alvo de forte contestação social. Embora não incida diretamente em questões de reabilitação urbana, de acordo com Lavadinho (2013), trata-se, essencialmente, de um diploma que tem como objetivo primeiro a extinção dos contratos de arrendamento celebrados antes da década de 1990, sem garantia de direitos aos inquilinos. A crescente procura de arrendamento em consequência da crise do mercado da construção e do imobiliário e a ausência de oferta de arrendamento a preços acessíveis determinaram que a reforma do arrendamento urbano fosse assumida como um objetivo prioritário no domínio da habitação. De fato, a reforma do arrendamento urbano de 2006 não conseguiu dar uma resposta suficiente aos principais problemas com que se debate o arrendamento urbano, especialmente os relacionados com os contratos com rendas anteriores a 1990, com a dificuldade de realização de obras de reabilitação em imóveis arrendados e com um complexo e moroso procedimento de despejo. ${ }^{5}$
O NRAU impõe um mecanismo de atualização de rendas que tem originado valores incomportáveis para muitos inquilinos sem que estejam estabelecidos os apoios sociais adequados e necessários, afetando as famílias de mais baixo estatuto socioeconômico. 0 desalojamento tem sido uma marca da nova lei do arrendamento, uma vez que permite-se a facilitação da ação de despejo caso o senhorio/ proprietário alegue pretender a casa para sua habitação própria ou dos descendentes, ou quando alega desejar realizar obras mais estruturais. A verdade é que a legislação não exige nem define que os alojamentos tenham de reunir as condições necessárias de habitabilidade, embora permita a ordem de despejo sem custos adicionais para o senhorio.

Nesse contexto, e já desde 2004, criou-se um quadro de referência para iniciativas de mercado livre no tocante à reabilitação urbana, convencionando o celebrar entre o município, ou a SRU constituída para o efeito, e os promotores privados, um contrato nos termos do qual as partes, dotadas de uma quase plena liberdade negocial, ajustarão os termos em que o promotor privado procederá às operações de reabilitação urbana.

À exceção da última década, todos os programas de reabilitação urbana levados a cabo pelo Estado, desde meados dos anos 1970, fomentaram a reabilitação urbana e a conservação do edificado existente no centro histórico das cidades portuguesas de acordo com o interesse público e coletivo, como demonstra Aguiar (2000, 2014). Esse autor, numa descrição do essencial da experiência de conservação do patrimônio urbano de Guimarães (cidade situada no distrito de Braga, na região Norte de Portugal), destaca uma 
reabilitação urbana "para e pelas pessoas", contra a segregação produzida por eventuais casos de gentrificação. Mas também a conservação estrita dos valores identitários e de autenticidade patrimonial, preservando as qualidades referenciais existentes na arquitetura da cidade histórica, prolongando-as para um território submetido a um desmesurado processo de desenvolvimento e de transformação, bem como a garantia da continuidade das permanências essenciais de longo prazo (a cidade como monumento, na estrutura da sua morfologia e tipologia fundiária), conservando as qualidades formais já sedimentadas (a arquitetura erudita e vernácula que construiu, no tempo, o centro histórico).

Parece pertinente, neste sentido, reavaliar a hipótese avançada há 30 anos por Jean Rémy (1983, apud Rodrigues, 1992a) de anterioridade, senão mesmo autonomia, do processo de gentrificação relativamente à reabilitação urbana. Isto é, da anterioridade da procura de espaços centrais com determinadas especificidades socioespaciais, diante da oferta, às práticas dos produtores públicos ou privados do alojamento. Justamente porque o fenômeno da gentrificação parece ancorado em dinâmicas econômicas e sociais mais globais, muito embora, uma preocupação relativamente recente nas ações públicas com o "embelezamento" dos espaços centrais das cidades e com a estética dos mesmos, não seja de todo alheia ao processo de revalorização. Processo esse que, de forma indireta, encarecerá os valores imobiliários, sobretudo tendo em conta a tendência de evolução do quadro legislativo português relativo à reabilitação urbana.

\section{Considerações finais}

Em termos restritos a reabilitação urbana pode definir-se como uma ação de melhoramento significativo do estado de um alojamento ou de um imóvel, e a intervenção sobre o ambiente construído é menos radical do que no caso da renovação, pois consiste em arranjar o existente e não em substituí-lo por novas construções (DGOTDU, 2005). Por vezes, essas ações de reabilitação resultam da própria iniciativa dos proprietários (ocupantes ou arrendatários). No entanto - como uma ampla documentação dedicada a esse fenômeno no âmbito dos estudos urbanos demonstra - só se desenvolveram frequentemente desde o final dos anos 1970, no âmbito de procedimentos públicos que definiam um perímetro de intervenção e meios de ação específicos. Em qualquer dos casos, o objetivo dessas ações de reabilitação é sempre o de conferir ou de restituir ao alojamento, ao imóvel, e mais generalizadamente ao bairro, uma melhor imagem social e um maior valor econômico (Bourdin, 1979, 1980; Gonçalves, 2006).

Do ponto de vista social, a reabilitação urbana pode, em certos casos, levar a processos de transição populacional, uma vez que os antigos residentes, muitas vezes de camadas sociais menos favorecidas, vão sendo progressivamente substituídos por população das classes média-alta e alta que podem pagar as habitações reabilitadas. Contribui-se, por conseguinte, e neste caso específico, para a gentrificação que é, por definição, um processo de "filtragem social" da cidade. Despoleta-se um processo de recomposição social que opera 
no mercado de habitação e de forma mais vincada e concreta nas habitações em estado de degradação dos bairros tradicionalmente populares. Correspondendo à recomposição (e substituição) social desses espaços e à sua transformação em bairros de classes média, média-alta, não se pode deixar de referir, por conhecimento desse processo de "substituição social", o reforço da segregação socioespacial na sua sequência, aprofundando a divisão social do espaço urbano e da sua fragmentação socioespacial. Contudo, nos bairros históricos de muitas das cidades portuguesas, a gentrificação denuncia um estádio ainda primário (primeira fase de quatro no total, de acordo com o modelo de estádios da gentrificação formulado por Clay em 1979), ainda em processo embrionário, de crescimento lento e esporádico, manifestando-se no espaço urbano de forma pontual e fragmentada, numa pequena escala circunscrita e limitada a apenas alguns fogos ou, quando muito, a alguns quarteirões de bairro. Essa situação é característica de outras cidades da Europa do Sul, sendo necessário distinguir essa gentrificação "marginal" dos moldes da gentrificação como estratégia urbana global ao serviço da cidade revanchista e da ofensiva neoliberal, modelo mais generalizado nas cidades do mundo anglosaxônico (Mendes, 2008, 2011).

A associação direta da gentrificação à reabilitação urbana merece, deste modo, maior discussão, sobretudo no caso português que é marcado por uma grande rigidez do mercado de habitação e por uma evolução de sucessivos pacotes legislativos desde meados do século XX que estabilizaram o mercado de arrendamento e limitaram fortemente a proliferação do fenômeno da gentrificação.
Beneficiando, em particular, as famílias de baixo estatuto socioeconômico e privilegiando a manutenção e a fixação da população autóctone, ou seja, já residente nos bairros antigos, os sucessivos pacotes legislativos relativos à conservação e reabilitação do parque habitacional funcionaram como um pesado constrangimento ao avanço da gentrificação, limitando o processo de substituição social inerente ao desalojamento dos grupos socioeconomicamente mais debilitados, que entretanto estariam em risco de serem deslocados pelos gentrifiers, os novos moradores, pertencentes a uma nova classe média alta e relativamente endinheirada (filtering up).

Aliás, como procuramos demonstrar, todos os programas de reabilitação urbana levados a cabo pelo Estado, desde meados dos anos 1970, fomentaram a reabilitação urbana e a conservação do edificado existente no centro histórico das cidades portuguesas em geral, de acordo com o interesse das populações autóctones já residentes nos bairros da cidade centro, contra a segregação produzida por eventuais casos de gentrificação. Ainda assim, a última década de política urbana para a reabilitação aponta para que as intervenções públicas que provocam valorização da cidade desencadeiem mecanismos contraditórios de expulsão e de reapropriação. As novas políticas de reabilitação urbana traduzem uma maior orientação para o mercado e para os consumidores, em detrimento das classes mais desfavorecidas. A seletividade dos investimentos favorável à reprodução do capital implica o abandono, 0 esquecimento e a menor atenção à "cidade da maioria", com particular gravidade para as áreas mais carenciadas onde se concentram os mais desfavorecidos. 
Assim, acompanhando esse processo de transição, se bem que as primeiras vagas de gentrificação, iniciadas nos anos 1960 e 1970, se resumissem a um fenômeno esporádico e de pequena escala: uma realidade causal e local, em certa medida até marginal, identificada apenas em algumas das cidades principais das economias de capitalismo tardio; a verdade é que, pelo contrário, na atualidade, uma perspectiva ampla dos efeitos da globalização nomeadamente os fluxos do capital global e em particular o setor financeiro - permite somar um novo caráter às atuais vagas de gentrificação desde os anos 1990. Esses efeitos promovem uma gentrificação em tudo diversa da anterior que foi observada durante décadas, quer do ponto de vista dos protagonistas e das procuras, como das modalidades e estrutura de oferta. 0 que antes era causal, marginal e local começa a ser sistemático, estando verdadeiramente globalizado a todas as regiões do planeta, como estratégia de dimensão significativa no panorama do urbanismo revanchista contemporâneo. Diversos estudos urbanos nos últimos anos têm relacionado o processo de gentrificação com as numerosas intervenções de renovação e regeneração urbanas, verificadas ao longo dos anos 1980 e 1990 em muitas cidades e por vezes favorecidas ou mesmo incentivadas pelas políticas neoliberais dos governos urbanos dirigidas à habitação. Na realidade, os próprios poderes públicos parecem reconhecer agora na gentrificação uma oportunidade de revitalização, ou regeneração urbana. Oportunidade essa cuja margem de lucro e de eficácia será tão maior quanto maior for a parcela do processo colocada estrategicamente sob o domínio do mercado e do setor privado (Smith, 2002; Slater, 2004). Esses tipos de proposta evitam claramente a questão da natureza de poder de classe e, de forma estratégica, enfraquecem - pelo menos indiretamente - a percepção dos conflitos urbanos no acesso ao alojamento na cidade centro. Isso tudo porque o Estado capitalista, por via das políticas de reabilitação urbana, assume-se como mediador da luta de classes que a gentrificação materializa no espaço urbano.

Neste contexto, a política de reabilitação urbana em Portugal tem enquadrado uma ação por parte dos agentes econômicos e de produção do espaço, e convencido a sociedade civil em geral e, em particular, a população residente nos bairros populares da cidade centro, das mais-valias da conservação do edificado pelo mercado e pelo setor privado, pelo que seus destinos passam a estar ligados aos do Estado capitalista e, consequentemente, todas as recomendações de mudança apontam apenas para um planeamento urbano mais eficaz, o que só reforça as funções do próprio Estado capitalista, em grande medida, em defesa dos interesses dos grupos privilegiados. Essa dinâmica foi também especialmente notória no nível das políticas municipais de reabilitação de outros países europeus nos casos em que o objetivo das intervenções urbanas de requalificação do patrimônio conseguiu dominar os movimentos de reforma e de resistência. A tendência da tecnocracia para dominar ou influenciar as lutas urbanas é facilitada pela capacidade de absorver o discurso dessas últimas e reintegrá-lo no da reforma urbana em geral (Harvey, 2011). A própria natureza dos problemas urbanos facilita esse controle social. Na resolução dos problemas urbanos (ex: crise de alojamento, deficiente rede de transportes públicos, etc.), as contradições do capital colocam-se como 
problemas de distribuição e de circulação, mais do que como problemas de produção. Para o planejamento urbano, as questões sociais levantadas pela ausência de habitação disponível na cidade centro ou pela procura insolvente de habitação pelos grupos mais desfavorecidos nunca se referem ao processo de produção sobre o qual a posição de classe assenta ou do qual deriva toda a estrutura desigual de classe, desenvolvimento urbano diferenciado e consequente luta de interesses, mas às medidas a tomar pelo Estado.

As ações de reabilitação urbana, privadas ou públicas, apenas constituem um aspecto dos processos socioespaciais que concorrem para a revalorização dos imóveis nas áreas centrais das cidades, por via do retorno do capital imobiliário nelas investido. A compreensão das operações de melhoria do parque habitacional, quer sejam "espontâneas" ou institucionalizadas, devem igualmente ser compreendidas à luz dos movimentos da população, das estratégias residenciais, das mudanças socioculturais, mas, e sobretudo, no âmbito dos movimentos cíclicos de capital diferenciadamente investido que favorecem uma requalificação de certos espaços urbanos, e, muito particularmente, dos antigos bairros centrais históricos, em detrimento de outros menos proveitosos como oportunidade de negócio imobiliário no sentido de não garantirem tão eficazmente uma reprodução de capital investido (Smith, 1987b, 1992). A obra smithiana convida-nos a repensar as estruturas profundas nas quais assentam os novos padrões de (re) desenvolvimento urbano, sobretudo à luz dos tempos incertos presentes de crise capitalista mundial.

\section{Luís Mendes}

Universidade de Lisboa, Instituto de Geografia e Ordenamento do Território. Lisboa, Portugal. luis.mendes@ceg.ul.pt

\section{Notas}

(1) A regeneração urbana consiste numa visão abrangente e integrada, que visa a resolução de problemas urbanos e que procura gerar mudanças duradouras no nível da condição econômica, física, social e ambiental de áreas que tenham sido sujeitas a transformações/alterações. [Tradução do autor]

(2) Não é preocupação central do presente texto problematizar a definição conceitual de gentrificação, pois existe uma abundante literatura científica que versa precisamente sobre esta questão, sendo o núcleo central das características do processo relativamente consensual entre a comunidade científica nacional e internacional. Para aprofundar a discussão do conceito, remetemos para toda uma ampla bibliografia internacional discutida em português em Rodrigues (1992a, 1992b, 1993, 1999 e 2010) e Mendes (2008). 
(3) A promoção da gentrificação como tributária da regeneração urbana passa, neste contexto mais recente, por dois tipos de estratégia: a de exploração de existência de uma base econômica forte, inovadora e com potencial de internacionalização; e a de aposta num determinado evento de projeção supranacional. Na concretização dessas estratégias o recurso à gentrificação (aqui entendida num conceito mais lato e amplo) afigura-se imprescindível, principalmente através dos projetos de flagship development, apostando na recuperação das frentes ribeirinhas, na criação de polos tecnológicos e de serviços, parques temáticos, complexos de congressos e exposições ou então em grandes operações urbanísticas, sustentadas ou não, por acontecimentos de projeção internacional.

(4) Artigo 82 da Lei n. 67-A/2007, de 31 de dezembro, que criou o Regime Extraordinário de Apoio à Reabilitação urbana.

(5) Informação disponível em: http://www.portaldahabitacao.pt/pt/nrau/home/. Acesso em: 2 set 2013.

\section{Referências}

AGUIAR, J. (2000). Dossier da Candidatura de Guimarães a Patrimônio Mundial. A experiência de reabilitação urbana do GTL de Guimarães: estratégia, método e algumas questões disciplinares. Lisboa, Faculdade de Arquitetura da Universidade Técnica de Lisboa. (Policopiado)

(2014). "A cidade consolidada: da renovação para a reabilitação urbana". In: CONFERÊNCIA “BOAS PRÁTICAS NA REABILITAÇÃO URBANA”. Lisboa, Câmara Municipal de Lisboa.

APPLETON, J. et al. (1995). Manual de apoio à reabilitação dos edifícios do Bairro Alto. Lisboa, Câmara Municipal de Lisboa.

ATKINSON, R. (2003). Domestication by Cappuccino or a revenge on urban space? Control and empowerment in the management of public spaces. Urban Studies, v. 40, n. 9, pp. 1829-1843.

ATKINSON, R. e BRIDGE, G. (2005). Gentrification in a global context: the new urban colonialism. Londres, Routledge.

BARATA SALGUEIRO, T. (1983). Mercado de habitação e estrutura urbana na área suburbana de Lisboa. Lisboa, Centro de Estudos Geográficos da Universidade de Lisboa.

(1994). Novos produtos imobiliários e reestruturação urbana. Finisterra, v. 29, n. 57, pp. 79-101.

BOURDIN, A. (1979). Restauration réhabilitation: I'ordre symbolique de l'espace neo-bourgeois. Espaces et Sociétés, n. 30/31, pp. 15-35.

(1980). Réhabilitation des vieux quartiers et nouveaux modes de vie. Recherches Sociologiques, v. 11, n. 3, pp. 259-275.

CLAY, P. (1979). Neighborhood renewal: middle-class resettlement and incumbent upgrading in American neighborhoods. Massachusetts, D.C., Health, Lexington. 
CML (1993). Reabilitação urbana nos núcleos históricos. Lisboa, Pelouro da Reabilitação Urbana da Câmara Municipal de Lisboa.

(2012). Estratégia de reabilitação urbana de Lisboa: 2011-2024. Lisboa, Câmara Municipal de Lisboa.

DGOTDU (2005). Vocabulário de termos e conceitos do ordenamento do território. Lisboa, Direção-Geral do Ordenamento do Território e Desenvolvimento Urbano.

GONÇALVES, J. (2006). Reabilitação urbana: oportunidades económicas, emprego e competências. Lisboa, Espaço e Desenvolvimento.

GOTTDIENER, M. (1985). The social production of urban space. Austin, University of Texas Press.

HACKWORTH, J. (2007). The neoliberal city: governance, ideology and development in American urbanism. Nova York, Cornell University Press.

HALL, T. (1998). Urban geography. Londres, Routledge.

HARVEY, D. (1975). The geography of capitalist accumulation: a reconstruction of marxian theory. Antipode, n. 7, pp. 9-21.

(1978). The urban process under capitalism. International Journal of Urban and Regional Research, n. 2, pp. 101-131.

(1985). The urbanization of capital. Oxford, Blackwell.

(2001). Spaces of capital. Towards a critical geography. Londres, Routledge.

(2006). Spaces of global capitalism. Towards a theory of uneven geographical development. Londres, Verso.

(2010). The enigma of capital and the crisis of capitalism. Oxford, Oxford University Press.

(2011). Le capitalisme contre le droit à la ville: neoliberalisme, urbanisation, résistances. Paris, Éditions Amsterdam.

(2012). Rebel cities: from the right to the city to the urban revolution. Londres, Verso.

(2013). Para entender o capital: Livro I. São Paulo, Boitempo.

(2014). Seventeen contradictions and the end of capitalism. Oxford, Oxford University Press.

LAVADINHO, R. (2013). A nova lei do arrendamento. Seara Nova, n. 1724, pp. 21-24.

LEES, L. (2008). Gentrification and social mixing: towards an inclusive urban renaissance? Urban Studies, v. 45, n. 12 , pp. 2449-2470.

LEES, L.; SLATER, T. e WYLY, E. (2008). Gentrification. Londres, Routledge.

LEES, L.; IMRIE, R. e RACO, M. (2009). Regenerating London. Governance, sustainability and community in a global city. Londres, Routledge.

LEFEBVRE, H. (1972). O pensamento marxista e a cidade. Póvoa de Varzim, Ulisseia.

(1974). La production de l'espace. Paris, Anthropos. (Edição inglesa: LEFEBVRE, H. (2003). The production of space. Oxford, Blackwell).

MATIAS FERREIRA, V. (2004). Fascínio da cidade. Memória e projecto da urbanidade. Lisboa, Centro de Estudos Territoriais do ISCTE, Ler Devagar. 
MAYER, M. (2007). “Contesting the neoliberalization of urban governance”. In: LEITNER, H. et al. (eds.). Contesting neoliberalism urban frontiers. Londres, Guilford Press.

MENDES, L. (2008). A nobilitação urbana no Bairro Alto: análise de um processo de recomposição socioespacial. Tese de mestrado. Lisboa, Universidade de Lisboa. (Policopiado.)

(2011). Cidade pós-moderna, gentrificação e produção social do espaço fragmentado. Cadernos Metrópole. São Paulo, v. 13, n. 26, pp. 473-495.

(2013). A regeneração urbana na política de cidades: Inflexão entre o fordismo e o pósfordismo. Urbe. Revista Brasileira de Gestão Urbana, v. 5, n. 1, pp. 33-45.

PACIONE, M. (2001). Urban geography. A global perspective. Londres, Routledge.

RODRIGUES, W. (1992a). Urbanidade e novos estilos de vida. Sociologia, Problemas e Práticas, n. 12, pp. 91-107.

(1992b). Retorno à cidade e emergência de novos estilos de vida. O fenômeno "gentrification" como exemplificação. Lisboa, ISCTE.

(1993). “Urbanidade e novos estilos de vida. Contributos para um debate”. In: II CONGRESSO PORTUGUÊS DE SOCIOLOGIA. Actas. Lisboa, Editorial Fragmentos e Associação Portuguesa de Sociologia.

(1999). Globalização e gentrificação: teoria e empiria. Sociologia, Problemas e Práticas, n. 29, pp. 95-125.

(2010). Cidade em transição. Nobilitação urbana, estilos de vida e reurbanização em Lisboa. Oeiras, Celta.

SANTOS, M. (1979). Economia espacial. Críticas e alternativas. São Paulo, Hucitec.

SAVAGE, M. e WARDE, A. (1993). Urban sociology, capitalism and modernity. Londres, Macmillan.

SILVA PEREIRA, R. (1963). Problemática da habitação em Portugal - I. Análise Social, n. 1, pp. 33-64.

SLATER, T. (2004). Municipality managed gentrification in South Parkdale, Toronto. The Canadian Geographer, v. 48, n. 3, pp. 303-325.

SMITH, N. (1979a). Toward a theory of gentrification: a back to the city movement by capital not people. Journal of the American Planning Association, n. 45, pp. 538-548.

(1979b). Gentrification and capital: theory, practice and ideology in Society Hill. Antipode, v. 11, n. 3, pp. 24-35.

(1982). Gentrification and uneven development. Economic Geography, n. 58, pp. 139-155.

(1984). Uneven development: nature, capital and the production of space. Oxford, Blackwell.

(1986a). "Gentrification, the frontier, and the restructuring of urban space". In: SMITH, N. e WILLIAMS, P. (eds.). Gentrification of the city. Londres, Allen e Unwin.

(1986b). The gentrification of Harlem? Annals of the Association of American Geographers, v. 76, n. 3, pp. 347-365. 
SMITH, N. (1987a). Gentrification and the rent gap. Annals of the Association of American Geographers, v. 77, n. 3, pp. $462-465$.

(1987b). Of yuppies and housing: gentrification, social restructuring and the urban dreams. Environment and Planning D: Society and Space, v. 5, n. 2, pp. 151-172.

(1992). Blind man's buff, or Hamnett's philosophical individualism in search of gentrification. Transactions of the Institute of British Geographers, v. 17, n. 1, pp. 110-115.

(1996). The new urban frontier. Gentrification and the revanchist city. Londres, Routledge.

(2001). "Rescaling politics: geography, globalism, and the new urbanism”. In: MINCA, C. (ed.). Postmodern geography. Theory and praxis. Oxford, Blackwell.

(2002). New globalism, new urbanism: gentrification as global urban strategy. Antipode, v. 34, n. 3, pp. 427-450.

(2005). "El redimensionamiento de las ciudades: la globalización y el urbanismo neoliberal". In: HARVEY, D.; SMITH, N. (eds.). Capital financiero, propiedad inmobiliaria y cultura. Barcelona, Universidade Autônoma de Barcelona.

VILLAÇA, F. (1998). Espaço intra-urbano no Brasil. São Paulo, Nobel.

Texto recebido em 20/out/2013

Texto aprovado em 25/mar/2014 
